\title{
FACTORES ARGUMENTATIVOS Y CORRELATOS SINTÁCTICOS
}

\author{
Catalina Fuentes Rodríguez \\ Universidad de Sevilla \\ cfuentes@siff.us.es
}

\section{Resumen}

Argumentation is a discourse dimension which show several categories. The speaker uses specific syntactic structures to express them. We are analysed the syntactic expression of "fuente" (source or backing) or "enunciador", the reserve, and the argumentative scale.

1. En la relación sintaxis-argumentación generalmente la dirección ha ido de la primera a la segunda: partimos de las estructuras sintácticas y analizamos sus efectos argumentativos, sus usos pragmáticos. En este caso queremos seguir el procedimiento inverso: partir de la dimensión argumentativa, presente en la mayoría de los textos, y buscar aquellas estructuras sintácticas de que el hablante dispone para expresar cada uno de los componentes.

¿Por qué hacer eso? Precisamente porque nos hemos encontrado algunas construcciones difíciles de encajar dentro de una visión sintáctica tradicional. Como mucho, se las incluye en las estructuras - periféricas $-^{1}$, pero sin ahondar más en ello. Necesitamos la vertiente argumentativa, porque están creadas precisamente para dar cuenta de sus funtores.

Como miembros del esquema argumentativo retomamos los establecidos en C. FuentesE. Alcaide (2002: 37) ${ }^{2}$.

\section{$\mathrm{A}(\mathrm{m}) \mathrm{C}>\mathrm{C}(\mathrm{m})$ \\ $\square$ topos y base argumentativa}

-

A los argumentos (A) y conclusiones 8 añadimos el topos y la base argumentativa como dos componentes distintos, y el marco argumentativo, que también es otro elemento específico.

La modalidad (m) es un calificador o modificador posible tanto de argumentos como conclusiones.

Veamos ahora cómo estos componentes utilizan la sintaxis para manifestarse creando nuevos huecos o funciones hasta ahora no descritas.

\footnotetext{
1 Hoy día es muy frecuente recurrir a este concepto. Así en I. Bosque-V. Demonte (eds., 1999) lo encontramos para la mayoría de las funciones.

2 Cfr. para una profundización en el tema.
} 
2. Para expresar la fuente, entendida por nosotros como el Enunciador, aquel que asume la responsabilidad de lo dicho ${ }^{3}$, nos encontramos con varios procedimientos, ya estudia$\operatorname{dos}^{4}$ :

- La impersonalidad: -Se rumorea que va a cerrar la empresa-

- La entonación marcada: -El declarante "olvidó" su relación profesional con el acusado-

- El imperfecto: -Mañana venía el director, ¿no?-

- El estilo referido, sobre todo el estilo directo, que plantea serios problemas sintácticos, ya que un enunciado perteneciente a un esquema comunicativo se -transporta- entero, con todas sus indicaciones contextuales, y se inserta en otro, al que sirven de marco ciertas indicaciones enunciativas.

Dotaremos al ejército, subrayó el presidente, de mejores infraestructuras para garantizar la seguridad

- los adverbios de evidencia o reafirmación, que ponen en marcha la presencia de un enunciador múltiple o público: Es toda la comunidad la que se presenta sosteniendo la afirmación:

Claro que los padres están para eso, para servir a los hijos

Evidentemente hay que realizar una selección, pero debe hacerse con honradez y justicia $^{5}$.

Pero, aparte de estas cuestiones, hay otros medios de los que no hemos hablado hasta ahora y que nos sirven para esta misma función: Señalar un enunciador distinto del hablante, ya sea un ser concreto, un individuo o ente lingüístico, o bien la comunidad. Nos referimos a ciertas construcciones, muchas de ellas parecidas en lo formal a los complementos circunstanciales de modo. Muestran al enunciador, ya sea en su acto de decir o de asertar. Son el complemento locutivo y el complemento de aserción ${ }^{6}$. Ambos utilizan las mismas estructuras sintácticas básicamente, pero sus funciones son diversas.

\subsection{Según + s.n. o pronombre}

según + oración con verbo dicendi, o de pensamiento, o modal.

Según establecería el punto de partida del decir (complemento locutivo o de la enunciación) y de la información (complemento de la aserción):

- Complemento locutivo: puede ser un ente individual el dicente o no. Cuando es un ente individual, puede ser nombrado personalmente o por el cargo:

3 Según O. Ducrot (1984) los enunciadores son "personas que el sentido mismo del enunciado da como responsables de tal o cual acto de lenguaje efectuado en la enunciación (acto ilocutorio o acto expresivo, por ejemplo)" (261). "Llamo «enunciadores» a esos seres que supuestamente se expresan a través de la enunciación, sin que por ello se les atribuyan palabras precisas; si ellos 'hablan' es sólo en el sentido de que la enunciación aparece como si expresara su punto de vista, su posición, su actitud, pero no, en el sentido material del término, sus manifestaciones concretas" (Ducrot, 208-9).

4 Cfr. C. Fuentes-E. Alcaide (2002), cap. 1.3., 109-157.

5 Cfr. C. Fuentes (1995), O. Ducrot $(1984,237$ y ss) y E. Ifantidon (2001).

6 Para su distinción vid. C. Fuentes (2003).

7 Este uso lo reconoce la RAE:A- + nombre o pronombre personal: con arreglo o conforme a lo que opinan o dicen las personas de que se trate.@, (DRAE, s.v.). 
Según Acosta, las cifras indican que un vuelo a Caracas cuesta una media de un 430\% más caro con respecto a cualquier destino americano con una distancia casi similar de separación, saliendo desde Madrid (Canarias 7, 29-11-2000)

Según él, en la suscripción de los mismos participaron el entonces Comandante General de las Fuerzas Armadas Jornadas, Abdel el Hafez, hoy en situación de retiro; dos representantes del Departamento de Ventas del ejército jordano; oficiales peruanos; y un representante del Gobierno de Estados Unidos, quien fungía de veedor para el cumplimiento de estos acuerdos (Caretas, 31-8-2000)

Según el concejal de Hacienda, Francisco Fernández Roca, "a estas alturas del plazo deben estar ya todos los recibos enviados a los vecinos, aunque estudiaremos si está habiendo errores en la recepción por parte de los ciudadanos". (Canarias 7, 24-11-2000)

En estos casos se apunta al que habla. Pero en el siguiente se le añade fuerza ilocutiva. Es enunciación + modalidad.

En declaraciones a la revista Premiere, que serán publicados en el número de noviembre, Oldman y su manager Douglas Urbanski-también productor del filme-protestaron contra la forma en que DreamWorks editó la película. Según ellos, el personaje de Gary Oldman aparece como un villano y no como el multifacético héroe republicano para el que se lo habia convocado.(Clarín, 17-10-2000)

A veces no es un sustantivo o un pronombre, sino un sintagma nominal más extenso:

Seguín la información que recibió de González, Pratini de Moraes señaló que Brasil posiblemente reanude sus importaciones de carne uruguaya en unos 90 dias, aunque ello dependerá de los análisis que realizarán periódicamente técnicos de ambos paises $(A B C$ Color, 7-11-2000)

Encontramos sustantivos que indican un acto de habla: información, informe, informado, denuncia..., y otros como: acuerdo, versión, censo, números, datos, plan, evaluación....

La fuente puede ser un periódico o una organización:

Según el mencionado diario, Fernando Millet paralizó la entrada en el Registro de la mencionada operación de compraventa para después ponerse en contacto con el empresario Juan Francisco Rosa, quien al parecer también estaba interesado en adquirir dicha finca (Canarias 7, 24-11-2000)

Según la radio israelí, Tannenbaum es coronel de reserva de la fuerza aérea y ejecutivo de una empresa de electrónica y de armamento israelies (Clarín, 17-10-2000)

Según fuentes acreditadas en esa ciudad, Bustamente puso el dedo en la llaga.)Esta secretaría sólo va a monitorear o también va a mediar?, habria preguntado (Caretas, 13$7-2000)$

Otras veces se utilizan verbos para expresar ese acto declarativo:

Según informaron a última hora de la tarde de ayer fuentes de la familia del niño, el Juzgado de Instrucción número dos de Coslada ya ha comunicado a la madre que el análisis del ADN de los huesos corresponde con la serie genética de los hermanos de Jonathan (Canarias 7, 29-11-2000)

- Complemento de aserción: Si en el complemento locutivo los verbos con los que se combina son de habla: reconocer, entender, afirmar, declarar, explicar, asegurar, replicar, informar, notificar, manifestar, aquí encontramos verbos de entendimiento y pensamiento: admitir, creer, pensar, opinar. $Y$ otros relacionados: trascender... 
Según se evidenció en pleno proceso de ingreso para el año 2000, los temas de exámenes se filtraron y algunos alumnos pudieron acceder a ellos (ABC color, 7-11-2000)

Según se supo, a raiz de esta situación, se optó por aplazar la reunión para esta tarde (idem)

Según pudieron constatar los ediles, Urunaga pretendia sobrefacturar el costo de los vehículos por un valor superior a los treinta millones de guaranies (idem)

En el caso de complemento de aserción, cuando va con un pronombre, este debe ser distinto a la persona yo, cosa que no ocurre con la otra preposición: para. Sin embargo, sí admite oraciones con verbos en primera persona o sintagmas con posesivos relativos al hablante: -según tengo entendido, según mi parecer, según mi opinión-.

El hablante aparece como el que responsabiliza de lo dicho, y esto puede hacerlo en mayor o menor grado (aserción fuerte-débil). Veamos los casos siguientes:

El comercio electrónico ha dado un giro espectacular, de acuerdo con ciertas noticias que llegan desde Gran Bretaña. Según parece, está en venta el mismísimo Sistema Solar y las transacciones correspondientes se pueden realizar por medio de Internet (Clarín, 910-2000)

Incluso en el caso siguiente aparece la modificación directa a un verbo afirmar:

Según estos criterios, puede afirmarse que cuando exista una relación entre la propiedad del capital y la distribución del beneficio, la empresa no es de Economía Social (Efimero, 00206012, 2000)

Puede ser otro enunciador el que asuma la responsabilidad de lo dicho:

Según los hechos considerados probados por el jurado popular, ese día Rafael Ortega, que habia cumplido los 18 años de edad sólo dos meses y medio antes, disparó con una recortada, arma que le habia entregado antes Evaristo José, un joven conocido en el Sur por su violenta personalidad, según las declaraciones de los testigos (Canarias 7, 9-2-2001)

2.2. Otra preposición que se utiliza para indicar el enunciador es para. Se subraya más la aserción que la pura enunciación, el puro decir. Se combina con nombres y pronombres:

Para estos moralistas, el presidente se ha convertido en un ente corruptor, sin esperanza de reconciliación, de exorcismo o de redención. Según ellos, los padres de la Constitución concibieron el proceso de destitución del presidente precisamente para quitar de en medio a seres malignos como él (El País, 16-1-99, 11)

Para el alcalde, Celestino Suárez, con la puesta en marcha de la potabilizadora se abre una nueva etapa para el desarrollo del municipio. "Hoy es un dia grande", dijo, (Canarias 7, 30/01/2001)

Para mi no fue penalti y me han comentado que por televisión se demuestra esto (Canarias $7,04 / 12 / 2000$ )

Para el presidente de Binter, "las soluciones o alternativas pasarian por compartir esfuerzos económicos entre el Gobierno canario y la aerolínea, que no pasarian por las subvenciones a la empresa sino a los viajeros" (Canarias 7, 29/11/2000)

Para el entrenador universitario la clave estará en la ambición que puedan exhibir sus hombres sobre el césped del Francisco de la Hera. "En Almendralejo tenemos que salir a jugárnosla porque la competición avanza y no podemos seguir descolgándonos de los puestos de salvación". (Canarias 7, 24/11/2000)

En este caso podría ser ambiguo. 
2.3. Como, por su parte, es una conjunción que aparece con una construcción oracional con verbo dicendi, en función de complemento locutivo:

Como afirma, sostiene

o como complemento de aserción:

Como es sabido,

Como era de esperar, -esto parece modal, de evidencia, introduce una oración de comentario

Incluso puede apuntar al interlocutor:

Como usted bien sabe,

En estos casos la fuerza argumentativa es mayor, porque la responsabilidad ya no recae en la comunidad, a la que el interlocutor puede oponerse al refutar lo dicho. Por el contrario, aquí tiene que oponerse a su propia opinión, autorrefutarse, con lo que la maniobra argumentativa es de lo más elaborada.

El estudio de como nos puede llevar a ver que es un término que se utiliza como marca del enunciador: indicando cuál es la fuente argumentativa, para conseguir un distanciamiento por parte del hablante, para dar fuerza a la argumentación, ya que la fuente está dotada de cierta autoridad. Para ello se usa este segmento, una oración subordinada aparentemente, entre pausas, y con cierta movilidad. Podemos pensar en una derivación del uso modal o comparativo, pero no parece encajar en ello. Por otra parte, como + oración antepuesta con pausa puede ser un circunstante condicional ( + subjuntivo) o causal (+ indicativo). Sin embargo, los casos que vamos a analizar tienen una función marginal, relacionada con el propio acto de comunicar, de enunciar, que no puede centrarse sólo en el verbo: decir y sus variantes (publicar, mencionar, explicar, afirmar, anunciar) sino otros componentes:

- puede ser el mismo acto de inferencia del receptor: como se desprende, se deduce,

- en otras ocasiones es un elemento de reafirmación modal: como es obvio, como es natural, como supongo que

- aparte de esto tenemos otros: como se sabe, sabemos, se recordará, es sabido, es de esperar... Apunta a ser algo conocido. Por tanto, o es un complemento de información, o un reforzador de fuerza informativa y argumentativa. Así como hace referencia a otras fuentes, a otros enunciadores (generalmente a la comunidad)

Esto mismo surge en oraciones independientes como comentario: como debe ser.

Veámoslo con detenimiento.

A) En primer lugar, como en posición antepuesta puede ir seguido de un verbo de habla: decir, recordar, anunciar... Introduce un complemento locutivo.

Como decía yo en campaña, cuando me dicen eso, que hay muchas promesas y que hay que cumplirlas, les contestaba yo cáleme, déjeme la oportunidad de servirles. (Fox en vivo, Fox contigo, 16/08/00, Radio ACIR, MÉXICO)

Como lo anunciáramos la semana pasada, este año el primer premio fue entregado al escritor y periodista Luis Freire Sarria, cuyo cuento "Se comienza por la mantequilla", un provocador alegato a favor de los encantos de la grasa para el paladar de un circunspecto cirujano plástico, fue la delicia del jurado. (Caretas, 13/07/2000)

Como afirmaba no ha mucho tiempo el inefable superobispo vasco Setién, "la paz tiene un precio". (Canarias 7, 07/03/2001) 
Como ha recordado en su comunicado el Consejo de la Prensa, no es la primera vez que Cáceres hace uso del único argumento persuasivo que parece conocer. (Caretas, 28/ 09/2000)

Pero Barrionuevo se acerca para preguntarles sobre la historia, la vida, la unidad del cosmos. Como señala, al sentir la presencia de estas ánimas andinas, el revoloteo de sus alas, el temblor de la tierra, ella los describe como seres de fuerza y luz, sabios seres quechuas que acompañan al hombre andino desde que el mundo es mundo. (Caretas, 28/ 09/2000)

Como muestra el mapa, Brasil tiene fronteras con diez países; el Perú, con cinco. (Caretas, 31/08/2000)

Como dije, yo ganaba muy buen dinero como abogado y en la bolsa, pero como cualquiera en mi profesión le diria, mucha tensión viene con este tipo de trabajo. (EFÍMERO, 00204028, 2000).

En este enunciado parece actuar como fuente de la enunciación y como elemento conector (no gramaticalizado, por supuesto) que enlaza con lo anterior y lo recoge.

Como decía Don José María Arizmendiarrieta, soporte ideológico del desarrollo cooperativo de Mondragón, "para hablar de cooperación y para que esta idea pueda cuajar en los hombres lo fundamental es que se trate de hombres para quienes existan valores superiores a la simple ganancia. (EFIMERO, 0020601, 2000)

En este último actúa como introductor del argumento de autoridad o fuente.

B) Como complemento de aserción, donde se expresa el grado de responsabilidad del enunciador ante lo dicho. Así tenemos algunos basados en las suposiciones del hablante:

Como supongo que este descontento no será sólo una cuestión personal, os escribo estas lineas para que contestéis todos aquellos que queráis además de comunicaros que como miembro de la Junta de Personal Docente e Investigador de la Universidad de Granada intentaré defender el mismo derecho que tienen nuestros compañeros más antiguos. (EFÍMERO, 00204024, 2000)

O casos de aserción más fuerte, de reafirmación, que tienen un adverbio paralelo:

En efecto, resulta más cómodo para los participantes escribir en las plantillas que aparecen en esta página web e imprimir después todo el documento. Como es natural, se permite añadir hojas fuera de plantilla cuando ello resulte necesario (por ejemplo, para incluir figuras). (EFIMERO, 00204027, 2000)

Como es obvio, el reglamento resulta indispensable para llevar a cabo el proceso hasta las últimas consecuencias. (Caretas, 28/09/2000)

En estos casos se presenta como algo que asume el que habla, al mismo tiempo que se basa en lo que para la comunidad es evidente. El efecto es el de enfatización informativa y refuerzo argumentativo. Frente al primer caso en que supongo lo establecía en una aserción débil, como es de suponer, expresión generalizadora, impersonal, tiene un mayor grado de fuerza. De nuevo alude a la comunidad, a la que se une el hablante y esto le hace pasar de la aserción débil a la fuerte:

Como es de suponer los familiares de nuestro político pusieron el grito en el Cabildo y en el Ayuntamiento, y lo que ocurrió nos dejó asombrados: después de estar marcada la carretera, (borrón y cuenta nueva! (Canarias 7, 05/02/2001) 
Tocaba fisgonear tras las ventanas porque correspondia a los vecinos del margen derecho impedir que tal apaño se llevara a cabo. Como es de suponer, no nos quedamos quietos y nuestras voces también llegaron al Ayuntamiento y al Cabildo. (Canarias 7. 05/02/2001)

En este último caso sí se considera algo conocido, deducido de lo dicho anteriormente. El hablante supone que el oyente va a llegar a esta conclusión, y él la verbaliza. Y parte de ella para comunicar los efectos o consecuencias.

El ex presidente Richard Nixon de los Estados Unidos tenía talento de sobra, además sabía lo que tenía que saber, pero al pretender espiar a los convencionales del Partido Demócrata no fue justo ni, en especial, fue honesto. Hizo ahi algo que la democracia no consiente. Y eso, en un país serio, sale caro. A Nixon le costó la presidencia. Como debe ser. (ABC Color, 20/10/2000)

Este enunciado independiente funciona como reafirmación.

C) En otros casos la información recae en las inferencias:

Como se desprende de la recién aprobada ORDEN de 26 de febrero de 1999, de la Consejería de Industria, Trabajo y. Turismo, reguladora de los Programas de Fomento del Empleo para 1999, que regula las ayudas de empleo, y como presumiblemente se recogerá en la próxima Orden de Fomento de la Economía Social para 1999, las empresas que soliciten alguna de las ayudas contempladas en estas normas, deberán acreditar que han realizado la correspondiente evaluación inicial de riesgos laborales de la empresa. (EFÍMERO, 00206013, 2000).

D) Otros casos de complemento de aserción, en que el hablante descarga responsabilidad en otros enunciadores, da lo dicho por conocido, son los siguientes:

Como se sabe, en el mundo se ha producido una alza espectacular del oro negro, que pasó de US\$10 el barril en enero de 1999 a más de US\$ 30 en las últimas semanas. Es una catástrofe incluso para países desarrollados. (Caretas, 28/09/2000)

(SIEMPRE NOS TOCA A LOS MISMOS! Como todo el mundo sabrá se ha aprobado recientemente la modificación del Decreto sobre Retribuciones del Profesorado Universitario (R.D. 74/2.000 de 21 de enero) como producto de la presión realizada durante el curso pasado por parte de todos los compañeros/as junto con los respectivos sindicatos y asociaciones. (EFIMMERO, 00204024, 2000)

Como sabéis, desde hace unos dias el acceso a Internet y al correo electrónico ya no es gratuito y debemos pagar cada una de las llamadas que desde los despachos hacemos al 808700, que no son pocas. (EFÍMERO, 00204019, 2000)

Igual que cuando aparece con otras construcciones.

Para el melómano este nuevo disco de Keith Jarrett tiene el valor adicional de un parte o un alta médico. Como es sabido, el pianista habia dejado de tocar desde 1996, aquejado por el llamado mal de fatiga crónica (un virus contraido en una gira de conciertos por Europa, según Jarrett). (Clarin, 17-10-2000).

Como suele suceder, Malvinas ha producido cataratas de pronunciamientos verbales y muy escasas conductas personales conducentes. (Clarin, 23/10/2000)

Como era de esperar, los ministros de Defensa trataron en Manaos el aspecto principal que afecta a la seguridad y la paz en la región: la presencia del narcotráfico como pode- 
rosa amenaza con capacidad de desestabilizar economias, gobiernos y sociedades. (Clarín, $23 / 10 / 2000)$

Son elementos de fuerza argumentativa a la vez que fuente de lo dicho ${ }^{8}$. Otras veces utilizamos expresiones menos habituales, pero semejantes a adverbios como naturalmente:

Como siempre ocurre, el proceso de seducción para "parejas comerciales" apasiona poco. Mas bien se trata de tratativas interminables. (Clarín, 23/10/2000)

3. Otro de los factores que intervienen en la argumentación es la escala de fuerza argumentativa, en virtud de la cual se evalúan argumentos y conclusiones. Esto hace muy frecuente la aparición de operadores argumentativos basados en la cuantificación, y en ellos puede ser necesaria la expresión de la escala que sirve de punto de referencia.

Hay elementos que tienen como escala -lo comúnmente admitido-, -lo considerado normal por la comunidad-. Así, en -Este piso es bastante grande-, se presupone con respecto a lo que se ve generalmente. Pero si queremos utilizar otra escala necesitamos su expresión. Para ello tenemos complementos de gradación o complementos de proporción ${ }^{9}$, función que creemos debe quedar definitivamente establecida en nuestra sintaxis.

Entre ellos encontraremos los complementos de los superlativos:

He encontrado a la persona más sorprendente de Andalucia

$\mathrm{O}$ estructuras consideradas concesivas por algunos ${ }^{10}$ :

Es muy rápido para su edad

Para no ser de aquí, conoce a mucha gente

$\mathrm{Y}$ se establecen incluso correlaciones tópicas:

Para ser albañil, es muy amable

Es bastante guapo para ser cirujano

En todas ellas nos salimos de lo normal, pero el complemento con para, en este caso, es el que expresa la escala. El efecto argumentativo que tenga el enunciado, o modal (la negación, la duda sobre lo dicho), surge de su adecuación al contexto, a la realidad comunicativa y social en que uno se mueve.

Esta estructura con para ha tenido diversas interpretaciones. C. Sánchez López (1995) abre la polémica al considerarlas -construcciones concesivas-: -Había mucha gente en la piscina para ser lunes-. Para que las construcciones con para sean interpretadas concesivamente es requisito la presencia imprescindible de un cuantificador en la principal, en este caso el SN -mucha gente-. Para ella, ese cuantificador se mueve en Forma Lógica para tomar dentro de su ámbito el SP (preposicional) encabezado por para, que resulta ser así una entidad cuantificada.

Existe otra interpretación posible para esta oración, que aquí llamaremos consecutiva, según la cual -a juzgar por la gente que había en la piscina, no es probable que fuera lunes-. La diferencia semántica entre ambas lecturas es evidente, pero la ambigüedad puede surgir, dado que también las oraciones consecutivas implican cuantificación.

C. Sánchez relaciona estas estructuras con lo que Salvá denomina Complementos de -suficiencia-o -proporción-: 
Es muy joven para conducir

Es muy tarde para ir al cine.

Su propuesta consiste en lo siguiente:

El Sp encabezado por para es complemento de un cuantificador, respecto del cual establece una proporción.[...] Las construcciones concesivas con para son constituyentes extraoracionales, es decir, adjuntos a la oración, en tanto que en su interpretación consecutiva tales construcciones parecen ser constituyentes intraoracionales, adjuntos al SV. [...] La concesividad es una noción derivada de otras estructural y genéticamente previas a ella que surge sobre todo en contextos en los que se combinan determinadas escalas pragmáticas con estructuras cuantificadas (C. Sánchez: 1995, 101)

Esta autora recuerda y se apoya en interpretaciones que hablan de sintagmas de grado (Sáez: 1994) o complementos de medida y proporción, y de ahí concluye que la construcción que estudiamos es un sintagma cuantificado en el que el cuantificador subcategoriza un complemento preposicional que podemos denominar de suficiencia, insuficiencia, mesura o desmesura. El núcleo $G$ puede estar ocupado por un cuantificador vacuo debido a la naturaleza escalar o gradual del núcleo que puede ser un Sintagma Adjetivo o un Sintagma Adverbial. Para puede introducir complementos de un elemento cuantificado.

El valor concesivo con para también exige en algún momento de la derivación estar bajo el ámbito de un cuantificador, aunque no sea aparentemente complemento de él.

La ambigüedad entre la interpretación concesiva y consecutiva desaparece según esta autora porque hay diferencias semánticas. En la interpretación consecutiva no hay que presuponer nada, se da la relación entre una causa y un efecto. En la concesiva hay que presuponer que A implica no B. Establece distintas pruebas pero las diferencias son contextuales o de topos, nunca gramaticales y de diferencia real.

Parece que nunca es posible que el sujeto del infinitivo coincida con un argumento de la oración principal si ese es el elemento cuantificado que legitima la interpretación concesiva de la subordinada.

Los sucesivos ministros de economia dejaron sin trabajo a muchos obreros para ser socialistas/*para ser necesarios

Hoy hay mucha gente en la piscina para hacer tan mal tiempo/ *para ser tan friolera.

Si este sintagma no está cuantificado sí puede correferir con el sujeto del verbo subordinado:

Sus amigos vendieron la moto a buen precio para ser tan malos negociantes/ para ser $\tan$ vieja.

C. Sánchez (1995) concluye que las propiedades cuantificacionales unifican tres construcciones diferentes, todas ellas introducidas por para:

a) Constituyentes cuantificados que subcategorizan un SP introducido por para al que hemos denominado de proporción, entendida esta como mesura, desmesura, suficiencia o insuficiencia y cuyo núcleo es un cuantificador que toma como complemento un SX graduable

b) Estructuras intraoracionales en las que un SP adjunto a SV es legitimado por el ascenso de un cuantificador a SF. Inducen una interpretación consecutiva cuyas implicaciones negativas obedecen a su naturaleza escalar (...). Son la versión no argumental de aquellos. 
c) Estructuras extraoracionales en las que una subordinada introducida por para que ocupa una posición adjunta a la or. pral (SF) es legitimada por un cuantificador que se mueve en FL (121-122).

La diferencia radica en el carácter factual de estas oraciones frente al implicativo o escalar de las de b.

De todo esto se deduce que el complemento de proporción es una visualización sintáctica de esa escala necesaria para poder argumentar y cuantificar. El efecto, cuando se contrapone a lo habitual, es la crítica, o concesión. Por ello, el efecto argumentativo que puede tener es el de negar esa realidad, porque no coincide con la escala.

J. A. Moya Corral (1996) critica en su obra esta interpretación. Para él estas construcciones no son concesivas ni sintáctica ni semánticamente, aunque tengan cierto matiz concesivo en una de sus lecturas. Razones:

- para subordina y es complemento de un cuantificador. Mientras que la concesiva es una interdependiente.

- Es semejante a las comparativas con de, sintáctica y semánticamente:

van introducidas por una preposición

son c. preposicionales que valoran un intensivo ${ }^{12}$

cuando llevan un verbo en forma finita necesitan un inclusor. $Y$ se pueden transformar una en otra:

\section{Habia mucha gente en la piscina para ser lunes}

Había en la piscina más gente de la que se espera en un lunes

Además, no tiene en cuenta C. Sánchez los valores más frecuentes. Así en: -Es demasiado listo para ser ministro-, se deduce: -es posible que sea ministro- o - no puedo creer que sea ministro-.

Como vemos, J. A. Moya en sus paráfrasis incluye ese -de lo que se espera--, por tanto se trata de una inadecuación entre la situación y la escala de referencia.

J. Martínez Álvarez (1997) también lo considera un caso en que no hay valor final, sino que actúa como complemento del cuantificador, aunque no cita a C. Sánchez López. Y habla de sentido, $o$-sustancia-concesiva. Esto viene motivado por la presencia de cuantificadores y contraposición en los términos lexemáticos.

En mi opinión, para es una preposición que indica el punto de referencia. Este es su sentido más genérico, que explicaría la diversidad de empleos que incluye. Este punto de referencia puede ser entendido como:

a) la meta, finalidad u objetivo

b) el enunciador o fuente

c) el marco en el que se sitúa la aserción, sobre todo si es cuantificador: -es alto para la edad que tiene-.

Moliner considera este un sentido adversativo de para, y nos indica que puede usarse como partícula adversativa, pero esto no es más que una consecuencia de ese empleo, no la razón en sí del mismo. 
Esta interpretación de para como punto de referencia la apoya también el hecho de que pueda usarse con alguna preposición: para con.

4. Hay otras estructuras que se utilizan para expresar la reserva argumentativa. Esta se define, según V. Lo Cascio (1998: 123) como: "Informaciones o datos que conducen a conclusiones o tesis hacia las que se está prevenido. Se trata de dudas y reservas sobre la validez $u$ oportunidad de la tesis que ya han sido preanunciadas del hecho de que la tesis o conclusión se acompañe por un operador modal, es decir, por un «calificador»".

Es una relación semántica, enunciativa, que supone una cierta -concesión-, una reformulación en la que lo dicho se somete a alguna variable. Esto ocurre en estructuras en las que al menos inicia un enunciado, y entre ellos se produce una relación de correferencia. En el segundo suele haber una relación de identidad referencial, sea por presencia o ausencia de un deíctico: "Al menos eso es lo que dicen".

Suelen ser enunciados parentéticos, en los que el hablante atenúa, reduce la fuerza de lo dicho, las implicaciones que pueda tener, a un nivel mínimo suficiente de la escala. Es una restricción, una atenuación, establecida sobre los efectos, la relevancia, o el alcance de ia enunciación. De este modo el hablante consigue no ser autosuficiente, no imponerse, mostrar cortesía lingüística, y, por otra parte, salva su imagen con ese comentario. La entonación es claramente la de un enunciado recordado en el momento. Otras veces se trata de un segundo enunciado que restringe o aclara el alcance del primero.

A. M. Marcovecchio (2002) la considera una estructura modal -minimizadora del valor de verdad - de una aserción, una concesiva modal. Se presenta con predicados de habla y opinión y con una deixis anafórica y explícita:

Este verano en la costa atlántica argentina será récord. Al menos así se asegura luego del millón de personas que $e^{13}$

Aquí no podemos decir que al menos sea un conector concesivo. La relación entre los dos enunciados no se manifiesta mediante un nexo. Sí con el anafórico (asi), y la relación semántica, la coherencia entre los hechos enunciados. El segundo suele ser un comentario sobre la aserción del primero:

Para Osvaldo Piazza no todo está perdido. Al menos, eso reflejan sus acciones. (Clarín, 11/10/2000)

De las indagaciones que, personalmente, han realizado dos dirigentes de la fundación FUNTEMAN en la Administración de Aduanas de Manta, se ha determinado que si ingresaron contenedores a nombre de la fundación. Al menos asi lo recuerdan personas que retienen documentación aduanera. (Blanco y Negro, 11/01/1998)

- Gustav Links, matemático de la Universidad de Leipzig -le respondo, ufano-. Al menos eso consta en mi expediente. ¿No lo ha leído? (J. Volpi: En busca de Klingsor, México)

En todos estos ejemplos se expresa una reserva, una atenuación sobre la fuerza del acto de habla del primer enunciado; atenúa las aserciones.

Pero es importante destacar la función de al menos. Este elemento sigue siendo, como en otros de sus empleos, un operador argumentativo, que sitúa lo dicho en un punto bajo de 
la escala, pero suficiente para el hablante. De ahí ese valor ascendente, positivo que tiene argumentativamente. Sería un MR, según lo establecido por Ducrot $(1995)^{14}$

Al menos modifica a cualquier categoría o sintagma. Incluso puede aparecer tras la preposición que introduce el sintagma nominal:

Después de al menos tres meses de encierro

En los casos que nos ocupan aparece modificando a todo el enunciado, presentando todo lo dicho como una opción baja pero suficiente. Se construye tras una afirmación general, y actúa como una restricción, es decir en un proceso descendente. Se comporta, pues, como MD.

Esta restricción puede darse de dos modos:

Porque introduce un comentario sobre la aserción previa, atenuando su fuerza. Pasamos de la fuerte a la débil o a su suspensión. O bien a adjudicárselo a otro enuncador. Aquí suelen aparecer deícticos para marcar la conexión entre ambos enunciados.

$Y$ si de aplausos se trata, los mayores, lógicamente, partieron de las miles de manos que ocuparon la tribuna visitante y cuyos dueños ahora se sienten iguales, al menos eso dice la tabla de posiciones, que el rutilante River y hasta se ilusionan con un título inédito en su historia.(Clarin, 17/10/2000)

De "disparate" han tildado los vecinos de El Polvorín la pretensión municipal de culminar la reposición de las viviendas este año. Y es que desde que se planteó el proyecto en 1991, sólo se han entregado 203 casas, esto es el 24\% del conjunto que hay en este barrio de la capital.

Asi al menos lo refleja la asociación de vecinos Mi Barrio en el primer boletín informativo que ha salido a la luz bajo el título "Dos milenios para reponer El Polvorin". (Canarias 7,08/01/2001)

Las chicas son... vaqueras. Por lo menos, eso es lo que ha decidido Gus Van Sant para su nueva película, la última producción de un director siempre polémico y personal. (EFÍMERO, 98104011, 1998)

Se detiene a saludarlo y cuando intenta hacerle alguna pregunta, la dueña de la bodega lo saluda efusivamente llamándolo señor Chacón. Sofian no recuerda el nombre. Al menos, cree que nunca le había dicho que se llamaba así. (Souza, Patricia, de; La mentira de un fauno, 1998)

En este último caso aparece en un enunciado correctivo.

Porque introduce un complemento añadido, que de esta forma resringe la extensión de lo dicho. Luego la afirmación, la aserción de lo dicho en el enunciado tiene que ser ahora reinterpretada con un aspecto nuevo, lo que hace que su campo designativo disminuya.

- O bien establece una restricción en la extensión de dicho enunciado. Aparece generalmente en un enunciado truncado, que presupone el anterior y se añade un complemento que restringe su extensión. Además, sitúa en el punto mínimo de la escala el cumplimiento de lo dicho. Esta extensión suele ser:

14 O. Ducrot (1995:147) define estos conceptos del siguiente modo: "Un mot lexical Y est dit 'MD' [modificador desrealizante] par rapporft à un prédicat X si et seulement si le syntagme XY: (i) n'est pas senti comme contradictoireM (ii) a une orientation argumentative inverse ou une force argumentative inférieure à celles de $X$. Si XY a une force argumentative supérieure à celle de $\mathrm{X}$, et de même orientation, $\mathrm{Y}$ est un MR [modificador realizante]» 
a) un complemento de referencia:

No exactamente-Bird trataba de sonar confiable-. Al menos no en el sentido habitual. Digamos que soy el encargado de vigilar que el profesor Einstein se sienta como en casa. Que nadie lo moleste. Soy su sombra. (Volpi, Jorge: En busca de Klingsor, 1999)

La vida no es así, al menos no para la mayoría de las víctimas de los desastres. (Clarin, $17 / 10 / 2000)$

MODELO A SEGUIR. Cincuenta años más tarde de la sorpresa que provocó Rashomon, de Akira Kurosawa, en Occidente, el cine de Asia sigue resultando un apasionante universo de contrastes, al menos para el espectador que lo observa a la distancia. (Clarín, 09/10/2000)

b) un complemento de modo:

El Equipo de Investigación comprobó que en la Argentina no existe ninguna firma que use ese nombre, al menos formalmente. (Clarín, 06/11/2000)

c) un complemento de tiempo, generalmente comparaciones:

La custodia fue traspasada a la Editorial Antártica, que debe mantenerlos en bodega. Al menos hasta nuevo aviso. (Hoy, 05-11/01/1998)

$Y$, como era de esperar a esa altura, ovacionaron a Lembo por su bestial patada a Gallardo. "Meta Uruguay", fue el grito más común. Pero no hubo caso. Fue derrota y otra vez volvió el silencio. Al menos, hasta el próximo clásico del Río de la Plata. (Clarín, 09/10/2000)

No ha sido frecuente - al menos desde el retorno de la democracia-que el partido de gobierno plantee demandas al Presidente como Alfonsin lo hizo ayer. (Clarín, 11/10/2000)

En este último aparece en un paréntesis de aclaración. En el siguiente encontramos por lo menos:

Andar dos o tres días no compensa. Y los otros caminos, el portugués y esto)no te Hombre, el portugués lo que pasa es que sólo hay un albergue alli, en Padrón, me parece. Por lo menos hace un par de años En Cesures. Cuando en Cesures, bueno, no sé. No sé. Por ahi hay uno nada más. Por lo menos hace un par de años sólo habia ése. No está tan promocionado, ni es tan habitual, entonces no está tan preparado. (Entrevista CSC004, hombre 24 años, 1998)

d) un complemento de lugar:

El Gobierno y la industria tienen una gran preocupación, por lo menos en el estado de Guanajuato, por desarrollar precisamente ese factor de la capacitación al mayor nivel posible, porque somos consientes que sin ella no podríamos competir internacionalmente. (Fox en vivo, Fox contigo, 21/10/00, Radio ACIR, MÉXICO)

e) un sujeto incluso:

CACHO: Cometimos ese crimen a los quince.

ANGEL: No cometimos nada. Por lo menos, yo no. (Ott, Gustavo: 80 dientes, 4 metros y 200 kilos, VENEZUELA, 1999)

f) $\mathrm{Y}$, sobre todo, un complemento de enunciador. Es el elemento mínimo de la escala, seguro y suficiente, al que se le imputa lo dicho, aunque ello no descarta la existencia de otros.

El sonido a plástico es más o menos aquel que se aleja de la naturalidad, de lo sencillamente grandioso. Y sus tres voces, sus tres gargantas, sus tres prodigios juntos, dejan de ser prodigios. Al menos para mí, que soy el que firma este comentario. (Época, 19/01/1998) 
Argumentativamente es el marcador de reserva. Expresa la atenuación sobre la fuerza de lo dicho, y la autoría de dicha aserción, la propia fuente de información. Así se protege la imagen el hablante. El que sitúe a un elemento en una posición en la escala hace que rechace los otros, por ello ese valor de contraposición. Es la afirmación de algo frente a un todo, de ahí el semantismo de menos, base léxica que se mantiene en por lo menos, variante del mismo.

Cada vez se habla menos de alienación o, por lo menos, no tanto como en la década de los 70. Pero la alienación sigue ahi, con temor incluso del trabajador a defraudar la expectativas depositadas en él. (Canarias 7, 14/03/2001)

Ese valor fórico lo encontramos en alguna otra combinatoria:

Ya que no puedo tener una obra original, al menos tendré una copia de museo(Galeria del coleccionista)

Al menos recoge lo dicho anteriormente, se contrapone a ello, situándose por debajo en la escala, indicando que el hablante valora como positivo el mantenerse dentro de la escala, y acepta lo dicho como suficiente argumentativamente.

El estudio de las formas con al menos en los datos obtenidos de la búsqueda realizada en el CREA, nos indica varios aspectos:

- en primer lugar, tendremos que decir que en estos casos al menos modifica a todo un enunciado. No tiene como ámbito un elemento o sintagma, sino todo el contenido de dicho enunciado.

- Asimismo presupone la existencia de un enunciado previo. ¿Por qué?

- porque generalmente consta de un complemento

- retoma todo lo dicho en el enunciado previo

- añade una corrección a algo dicho anteriormente (a menudo con $o$ ):

El feriado amortiguó en parte los efectos visibles de la medida de protesta, pero cuatro piquetes formados por productores rurales en la provincia de Entre Rios impidieron o, al menos, obstaculizaron el paso de todo tipo de camiones. (Clarin, 17/10/2000)

Aquí se ve claramente que se utiliza tras $o$, con un valor correctivo, añade un término que está más abajo en la escala: no se dice el término A, sino que se sustituye por otro más suave, con menos fuerza argumentativa.

El próximo curso está cerca y creo que es deseo de todos, al menos de los compañeros de Sevilla, poder tener prevista una organización de trabajos conjuntos de toda la Comunidad Andaluza y al mismo tiempo de poder encardinar las actividades de las distintas sedes para que pueda pensarse en una unidad. (Conversación del Grupo de Estudios Andaluz de la Escuela Europea de Psicoanálisis (GEA-EEP), Granada, 2000...)

En consecuencia, se trata de una restricción, una reserva argumentativa que se presenta como una atenuación o una corrección. Generalmente se presupone parte del primer enunciado. De ahí la afirmación de la necesidad de un deíctico (que no siempre aparece). Pero porque como podemos ver en el siguiente caso, la presencia de un deíctico no supone automáticamente esta relación de reserva:

Es un hecho que, por obra de las sorpresivas designaciones de la Corte Suprema, el gobierno quedará en una posición ligeramente menos inconfortable de lo que se habia previsto en el caso del Senado. Ello pudo facilitar el doble mensaje del Presidente Eduardo Frei, que junto con nominar a los dos senadores que le asigna la Constitución, criticó a la institución de los designados. Al menos eso deja en claro que el gobierno no se siente sa- 
tisfecho, o complaciente, con una disposición constitucional que no comparte, aunque esté obligado a acatarla y aunque haya tenido que desplegar su influencia (como obviamente lo hizo en el caso del ex canciller Enrique Silva Cimma) para inclinar el proceso en su favor. (Hoy, 29/12/1997-04/01/1998)

Aquí la relación es de consecuencia o conclusión. Por tanto, lo importante es la relación que se presupone que mantienen los dos enunciados.

Esta relación podría entrar en la llamada reinterpretación. Esta es a la aserción lo que la reformulación a la enunciación: es decir, un volver sobre ella:

Enunciación-Reformulación

Aserción-Reinterpretación

H. Nolke habla de la restructuración enunciativa como aquella en la que los dos segmentos se combinan en un nuevo enunciado más incluyente. Se sustituye la afirmación del primer enunciado por otro modalizado, matizado. Se diferencia de la reformulación en que es una relación que no se establece con nexo. Sería, pues, sintácticamente una yuxtaposición. En el contenido supone un añadido. No se anula lo dicho como en la reformulación, sino que añade una circunstancia, una restricción, o una modalidad. El efecto es la atenuación de la aserción:

En Occidente (¿en Hollywood?), el cine ha ido perdiendo su relación con el contexto, con el mundo que lo rodea. Son (al menos, parecen) películas que no se insertan en la realidad circundante. $O$, si es que lo hacen, parten de una aceptación tal que les permite ser tácitos al respecto. Son películas que existen fuera del mundo. (Clarín, 09/10/2000)

Al menos establece una orientación argumentativa de esta segunda aserción: es la mínima en la escala, aunque suficiente. Se pasa de una afirmación a una aserción del hablante. Este señala que es el ámbito mínimo en el que puede entenderse esa aserción. Al menos sigue siendo, pues, un operador, aunque su ámbito de actuación es todo el enunciado posterior, reducido, como hemos dicho, a un participante o complemento de referencia. Un enunciado que -después- de haber dicho el primero matiza, y en este caso restringe, la aserción al mínimo que resulta suficiente y seguro por parte del hablante.

El valor originario de al menos se mantiene: marca un elemento mínimo suficiente en la escala. Sólo que la conexión entre ambos enunciados, apoyado por el deíctico, hace que se utilice como mecanismo de reinterpretación. Establece, pues, una relación cohesiva entre enunciados, aparte de ser un operador argumentativo.

\section{Referencias bibliográficas}

Bosque, I. Demonte, V. (1999): Gramática descriptiva de la lengua española. Madrid, Espasa.

Cadiot, P. (1992): "Les constructions typico-prédicatives, entre l'énonciation et le parti pris". En W. de Mulder et al. (Eds.): Énonciation et parti pris. Actes du colloque de l'Université d'Anvers, Amsterdam-Atlanta, Rodopi, págs. 75-85.

Ducrot, O. (1984): "El decir y lo dicho", Buenos Aires, Hachette.

Ducrot, O. (1995): "Les modificateurs déréalisants", Journal of Pragmatics, 24, págs. 145-165.

Fuentes, C. (1995): "Polifonía y argumentación: los adverbios de verdad, certeza, seguridad y evidencia en español", Lexis, XIX,1, págs. 59-83.

Fuentes, C. (2003): "Enunciación, modalidad y aserción: tres clásicos" (en prensa).

Fuentes, C. y E. Alcaide (2002): Mecanismos lingüisticos de la persuasión. Madrid, Arco Libros. 
García Negroni, M. M. (1999): "Réinterprétation et connecteurs: le cas des connecteurs enchérissants et des connecteurs reformulatifs". En J. Verschueren (ed.): Pragmatics at 1998. Selected Papers fron the 6th international pragmatics conference, vol. 2, Antwerp, International Pragmatics Association, págs. 172-180.

Gutiérrez Ordóñez, S. (1994): Estructuras comparativas. Madrid, Arco Libros.

Ifantidou, E. (2001): Evidentials and relevance. Amsterdam, J. Benjamins.

Lo Cascio, V. (1998): Gramática de la argumentación. Madrid, Alianza.

Marcovecchio, A. M. (2002): "Concesivas oracionales: especificadores del valor veritativo, valorativas y metalingüísticas”, IV Congreso de Lingüística General, Área de Lingüística General. Cádiz, págs. 1707-1715.

Martínez Álvarez, J. (1997): "Construcciones periféricas con para", Gramma-Temas 2, págs. 333352.

Moya Corral, J. A. (1996): Los mecanismos de la interordinación: a propósito de "pero" y "aunque". Univ. de Granada.

Sánchez López, C. (1995): "Construcciones concesivas con para", RSEL, 25,1, págs. 99-123. 